\title{
Clinical Importance of Proper Questioning of the Companion of the Veterinary Patient During the Medical Consultation
}

\section{Marcelo Erik Zambrano Alarcón ${ }^{1}$, Jorge Luis Sánchez Palomino ${ }^{2 *}$, Sucel de la Caridad del Valle Valladares ${ }^{3}$, Juan Carlos Valverde Valverde ${ }^{4}$ and Edgard Joffre Avilés Camacho ${ }^{1}$}

${ }^{1}$ Faculty of Natural Sciences, University of Guayaquil, Ecuador

${ }^{2}$ Faculty of Agricultural Sciences, School of Veterinary Medicine and Zootechnics, Technical University of Babahoyo, Ecuador

${ }^{3}$ Camosun College, Victoria, BC, Canadá

${ }^{4}$ Faculty of Chemical Sciences, University of Guayaquil, Ecuador

*Corresponding Author: Jorge Luis Sánchez Palomino, Faculty of Agricultural Sciences, School of Veterinary Medicine and Zootechnics, Technical University of Babahoyo, Ecuador.

DOI: $10.31080 /$ ASVS.2022.04.0334

Anamnesis is the set of questions or interrogation that the clinician asks the patient's companion (animal owner, caretaker, or manager), before and during the clinical examination, whose answers will guide a probable diagnosis and establish the ideal treatment. To obtain the necessary information, the method that the clinician has, and his ability to relate to the patient and the owners or those responsible for them, is essential. You must know what to ask and how to ask. It is the science, and it is the art (because it requires qualities of intelligence and human talent), to elaborate a presumptive diagnosis, basing the clinician, on the questioning of the owner, without having physically and/or additionally examined the patient. Centuries have passed, wonderful discoveries have been developed for the benefit of patients, however, Anamnesis continues to be one of the most important pillars of medicine.

In veterinary medicine, signs are collected (objective manifestation of the disease) but not symptoms, since these are subjective manifestations, for which they are only perceptible by patients. The anamnesis is carried out not only on the animal or animals but also on the establishment, the environment, and the productive systems.

To learn how to question the patient's companion and obtain an adequate clinical history, an organized and objective guide is required. This is the only way to avoid the elaboration of ambiguous, superficial, disorganized, and redundant stories [7]. With the aim of contributing to the competent and comprehensive performance of the anamnesis in daily veterinary clinical practice, we will present key aspects to fulfill this purpose given its medical importance.

The terminology used in the questions must be clear and precise, to obtain answers of the same nature. In the first instance, the owner, companion, or manager will be allowed to tell the reason for the consultation and then start the questions. "The clinical experience, the science, the psychological insight and the moral authority of a physician are never better appreciated than when you listen to him while he collects the Anamnesis" [5].

Considering the age of the data, the anamnesis can be

- Present or current: the Interrogation will be about the current process that the patient suffers and what is the reason for the consultation.

- Past or remote: it is about investigating the health history of the animal(s), the diseases that the animal suffered, treatments and surgeries that were performed, the health plans applied, the parents' illnesses, among other aspects. These questions must contemplate the law of the "4 adverbs": 1 . Which one?: Illness or syndrome suffered, and intervening professional; 2. When?: On what date did it happen (start, duration and end); 3. How much?: The magnitude of the signology or its intensity; 4. How?: How was the treatment instituted (pharmacological, physical, dietary, hygienic, allopathic, homeopathic) and complementary tests performed. 
Depending on the number of animals, the anamnesis can be individual, when referring to or analyzing a single animal, or group when referring to a group (herd or animal population).

The anamnesis of the establishment collects data on health, vaccination regimens, percentage of animal replacement, exploitation systems, among other important aspects. Although the anamnesis constitutes a very important step in the clinical examination, the data obtained must be taken with caution, since there is a risk that the interlocutor is a person who is not very observant and intentionally omits or modifies data.

Key success factors to carry out an adequate interrogation, without order of importance

- The clinician must create an adequate environment for the anamnesis, master the techniques to be able to listen, demonstrating his clinical experience, his scientific knowledge, and his ethical power, to be able to psychologically penetrate the patient's companion, wasting tolerance, patience, understanding, intelligence, and talent.

- Assess the transparency of the informant, the usefulness of the data and its validity, using all the time necessary for it.

- Completely record the identification data of each patient.

- $\quad$ Give the practical importance that the reason for the consultation deserves; with tact and sagacity, be able to distinguish what is useful from what is not useful or doubtful.

- Avoid underestimating previous diagnostic judgments made by another doctor or by the patient's companion.

- $\quad$ Learn to question with respect and prudence.

- Know how to interpret the meaning offered by the answers, and instill confidence, poise, and wisdom through their verbal and extraverbal expressions.

- Delve into the analysis and writing of the history of the current disease.

- Briefly clarify the history or general state of health or disease before the onset of the current disease.

- $\quad$ Study the beginning date of the first signs as accurately as possible.

- $\quad$ Prioritize the signs from the onset of the current disease to the time of the interview: appearance, location, intensity, frequency, duration, evolution and accompanying or associated signs.
- $\quad$ Distinguish the possible behaviors followed by the patient's companion: investigations, pharmacological treatments (medications, doses), evolution or involution, progress, or other effects of the treatment(s).

- $\quad$ Study the full range of possible antecedents: Illnesses, (I inherit pathologies), allergies and intolerances, immunizations, surgical interventions, traumas, previous hospitalizations, usual therapies, observed habits and reproductive history, if any.

- Respect the individualities of the owner or companion of the patient, making them feel understood, protected, and helped by the clinician.

- And finally, the deep questioning, which cannot be avoided by systems and equipment, which includes questions aimed at identifying diseases, signs, or abnormal organic functions, without forgetting under any circumstances all aseptic and antiseptic procedures.

In daily practice, the questions that are asked during the anamnesis are conditioned by the previous answers of the companions, and not by questionnaires of specific printed signs, routine and not suitable, impractical or non-functional, for which it is recommended to have a written list of signs to be reviewed, attached to the clinical history, thus avoiding important omissions, allowing to go into details of the relevant signology that could be ignored for reasons beyond the control of the medical professional [1-7].

\section{Conflict of Interest}

There are no conflicts of interest or economics.

\section{Bibliography}

1. Andrew G., et al. "Manual of small animal endocrinology". $2^{\text {nd }}$. ed. UK: British Small Animal Veterinary Association (2008).

2. Baker R and Lumsden JH. "Color atlas of cytology of the dog and cat". Toronto: Mosby (2018): 26-66.

3. Davidson MG., et al. "Manual of clinical pathology in small species". Madrid: Harcourt; 2000.

4. Feldman BF., et al. "Schalm's veterinary hematology". 5a. ed. Philadelphia: Lippincott Williams and Wilkins (2000).

5. Jardon GH., et al. "Veterinary Clinical Pathology Practice Manual". Mexico: FMVZ/UNAM (2003).

6. Luis NO., et al. "Veterinary clinical pathology". Mexico: FMVZ/ UNAM (2005). 
7. Wikipedia. "Anamnesis".

\section{Assets from publication with us}

- Prompt Acknowledgement after receiving the article

- Thorough Double blinded peer review

- Rapid Publication

- Issue of Publication Certificate

- High visibility of your Published work

Website: www.actascientific.com/

Submit Article: www.actascientific.com/submission.php

Email us: editor@actascientific.com

Contact us: +919182824667 